\title{
Psychological biases abilities on constructing weekend anomaly
}

\author{
${ }^{1}$ Rayenda Brahmana, Hooy Chee-Wooi, Zamri Ahmad \\ School of Management, Universiti Sains Malaysia
}

Even though many researchers have proposed trading behavior as the explanation of the Monday Irrationality or Day-of-the Week anomaly, yet, it has still left without empirical evidence. This research aims to investigate empirically by gauging psychological approach whereas the affection bias (weather-induced mood, and moon-induced mood), and cognition bias (attention bias, and cognitive dissonance) are the factors. Our results report that investor's Monday irrationality is caused by those psychological biases. Employing one traditional dummy interaction model and an innovation model with market index returns and size-based portfolio returns as our constructs, we found the psychological biases are the explanations beyond the DOWA over the period of 1 January 1999 until 22 March 2010. This research found size does matter in this case as the intuitive judgment of investor plays role on investment decision. Our findings support the conclusion that psychology of investor does play important role on investment decision and resulting DOWA.

Keyword: Psychological Biases, Moon Phase, Weather Condition, Attention, Herd Behaviour, Day-of-the-Week Anomaly

JEL: D03, G12, G14

\section{INTRODUCTION}

Can traditional finance always assume that investors are rational? If yes, how to explain the market anomalies, especially the day-of-the week anomaly (DOWA) whereas the Monday returns are significantly dispersed compare to other weekdays? What is the explanation on this Monday irrationality? This major question becomes our main point in this paper.

Many scholars such as Abrahaham and Ikenberry (1994), Clare et al. (1995), Berument and Kiymaz (2001), Wong et al. (2006), and Yahyazadehfar (2006) have suggested trading behavior as the explanation on this weekend irrationality. Yet, it is rarely found an empirical paper investigating it; a gap that this research aims to fill. To tackle this gap, we propose psychological approach as the explanation of it. Specifically, this research addresses 5 psychological biases, which are weather-induced mood, moon-induced mood, attention sentiment, news sentiment, and cognitive dissonance, as the driven factors in this Monday irrationality.

The aim of this paper is to investigate the ability of the psychological biases on constructing the Monday irrationality. In regards of examine it, firstly, we employ the dummy interaction model. This model investigates whether there is an association between the biases and the return. If we find so, we proceed by looking whether the dummy interaction has significant relationship to the market. If there is significant association, we surmise that psychological biases are the antecedents of weekend anomaly.

Another model used in this research is separate day series model. We took the returns, temperature, moon phase dummy, bad news, attention, and herd proxy day by day and tested it one by one. For instance, we took Monday returns and tested it with Monday temperature, Monday full moon, bad news on Monday, Monday attention, and Monday herding. We did it the same with other trading weekdays. Our last resort in this research is by not only testing

\footnotetext{
${ }^{1}$ Rayenda Brahmana is the corresponding author
} 
the model with market index returns as the dependent variable, but also taking the size-based portfolio formation returns.

Our results on market index returns data confirm our proposition, where psychological biases have played important role on constructing the weekend anomaly. Our dummy interaction model shows that each psychological bias has significant relationship on the market returns. When we tested it further, only the interaction of Monday and psychological biases has the effect on the market signifying the role of psychological biases on Monday returns. Meanwhile, the robustness check confirms that the interaction of other days and psychological biases did not show any significant relationship. For this reason, we can conclude that the psychological biases are the factors of weekend anomaly.

Our results of this separate day-of-the week series shows the same conclusion with our interaction model. We found that those psychological biases only affect the Monday returns but not other weekday's returns. Consequently, this confirmation let us to conclude that the psychological biases are indeed the driver of weekend anomaly.

In our size-based portfolio data, we found that the psychological biases have effect on the middle-size portfolio's weekend anomaly. Partially, the psychological biases did also play important role on weekend anomaly of small size and big size portfolio. The small size portfolio is more to the cognition biases, and big size portfolio was affected by the affection biases (temperature and moon). Our robustness check of portfolio separate day-of the week series confirms this conclusion.

In a nutshell, we surmise that psychological biases have the abilities on weekend anomaly. It answers the suggestion of previous results that weekend anomaly is more to the investor trading behaviour. This research is a good step-stone in responding the inability of conventional finance to explain the anomalous condition in the market.

This paper contributes in two ways. First, it contributes to the body of knowledge. So far, there is rarely found an empirical explanation on the day-of-the week anomaly by trading behavior context. Our research advises empirically the psychological biases as the explanation. Moreover, it suggests that the efficiency in the market actually can be achieved as long as there is no psychological bias in the investor trading behavior. Second, it caters for the implication to practitioners by revealing that affection bias and cognition bias of another individual investor during Monday is good for active investing decision. Sophisticated investor can beat the market as long as controlling the psychology of other investors through affection bias or cognitive dissonance during Monday.

The remainder of this study is organized as follows. Section 2 delivers the literature review. Then, we deliver the methodology and data on section 3. Section 4 addresses the results and discussion. In the end of this paper, we surmise our research in section 5.

\section{Literature}

Firstly, let us label day-of-the week anomaly (DOWA) as Monday irrationality. DOWA or Monday Irrationality is an anomalous condition in the market where the Monday returns are significantly dispersed compare the other trading weekdays. In other words, the market on Monday tends to break up from its normal behaviour due the investor irrationality. This anomaly is indeed a contradictory evidence of the rational behavior assumption in conventional finance.

With regards to explain the rationalization behind this anomaly, finance scholars such as Abraham and Ikenberry (1994), and Wong et al. (2006) addressed trading behavior as the sine qua non of DOWA. However, rarely found a research has investigated it empirically; a literature gap that this study will contribute.

To answer this issue, this study elaborates the finance with the psychology perspective. This is in line with DeBondt \& Thaler (1995) argument stating a good finance theory has to 
be based on the evidence of the participants' psychology. Borrowing Ellis' ABC model from psychology area, this research proposes psychological biases as the drivers of DOWA. We propose 5 psychological biases which are weather-induced mood bias, moon-induced mood bias, attention sentiment, heuristic, and cognitive dissonance.

Figure 1 shows the connection between the psychological biases and DOWA. We adopted psychology theory called Ellis' ABC (Activating event, Bias in Belief, and Consequence) model to investigate the relationship. Ellis' $\mathrm{ABC}$ model argues that the behavior of human is the consequence of an activating event. In this study, the activating events are the high temperature, full moon, and cognitive experience. It affects human decision in framing the decision by giving the biases. The result from this biased decision making is irrationality whereas in this study we show it through Monday irrationality or DOWA. Next sub-sections discuss it in detail.

Figure 1 The Research Framework

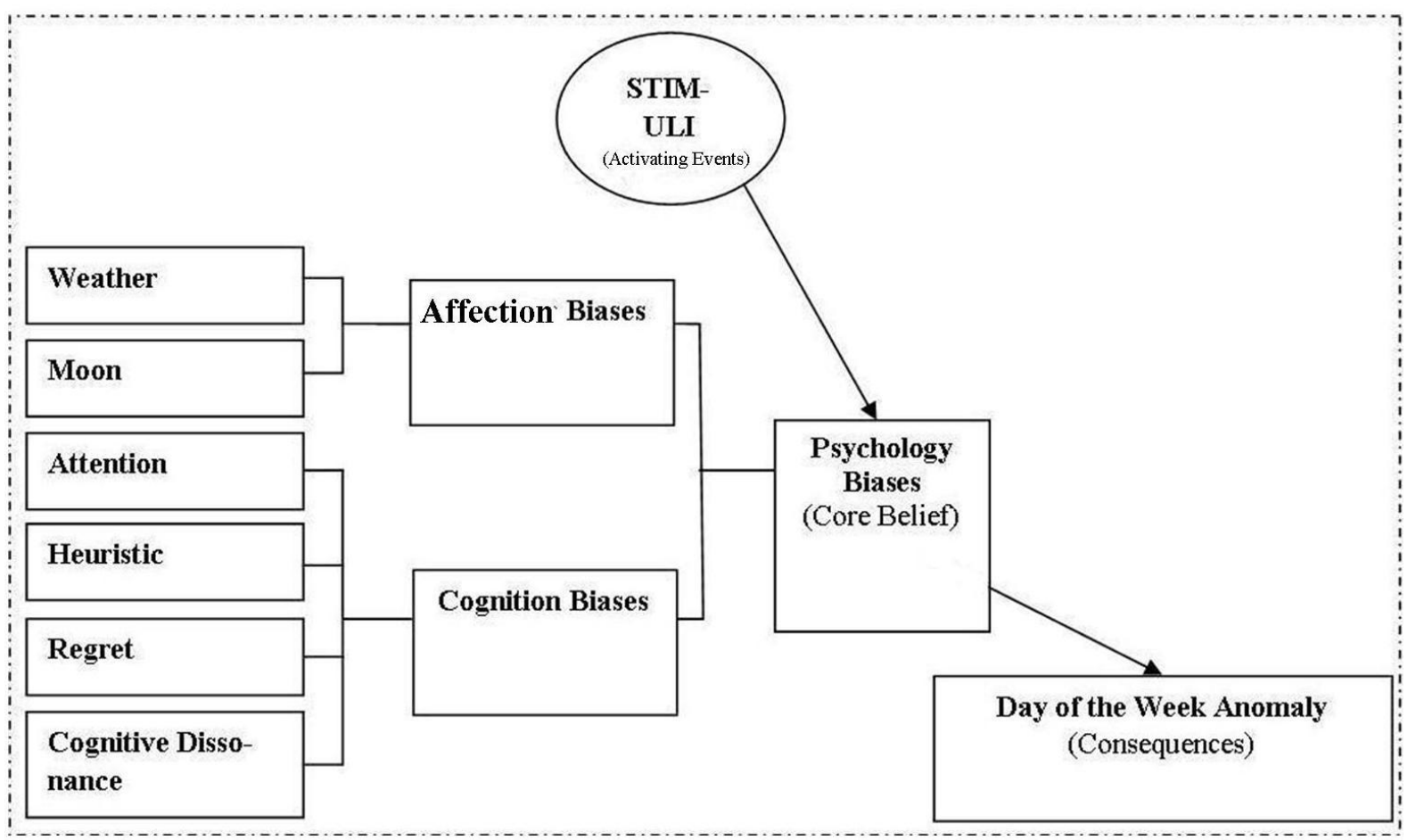

\subsection{Weather Condition and the Monday Irrationality / DOWA}

One of the proposed driver factors of DOWA is weather, which is an attribute to human mood disorder. As generally known, mood has contribution to the decision making. Schwarz and Clore (1983) found that people obtain more satisfaction when weather was luminous than when weather was reported rainy. Howarth and Hoffman (1984) addressed weather variables as the driver in individual's moods and as the factors of a particular behavior. In short, good weather provokes positive mood states, and conversely, bad weather provokes negative mood states.

The relationship between weather and human behavior actually has been investigated tremendously in environmental psychology. Hansen et al. (2008)'s study is an example. They investigated the effects of high temperature to mental, behavioral, and genitive disorders. By estimating the hospital admission and mortalities in the period of 1993-2006, they argued that high temperature caused a salient risk to mental health. This result is in line with prior study on the relationship of temperature and mental health such as Basu and Samet (2002), and Kovats and Ebi (2006).

Likewise in finance, the association between weather and financial market has also been investigated by many scholars. The pioneer is Saunders (1993) who found the relationship 
between the cloud cover level and the stock returns in New York. Further, he addressed that when the level of cloud cover was $100 \%$, the stock returns were significantly below average, and when the cloud cover level was $0-20 \%$, the stock returns were significantly above the average.

Further evidence of the relationship between weather and stock markets was also documented by Hirshleifer and Shumway (2003). They found the role of clouds cover on stock market but with broader market and longer period compare to Saunders (1993). Pardo \& Valor (2003) found the weather effect on the financial markets by affecting the behavior of market traders. Kramer and Runde (1997); Kamstra, Kramer, and Levi (2000); and Turfan and Hamarat (2003) filed a positive relationship between weather condition and stock market return. However, it is rare to find a study that investigated the link between moods and market anomaly.

Interestingly, we also discovered seasonality in global temperature. Depicted in Figure 2, the Monday temperature is relatively higher than that of other weekdays. The range of the Monday temperature is raised from around $26^{\circ}$ Celsius up to around $33^{\circ}$ Celsius. Meanwhile, the other days' temperature range is in between $16^{\circ}$ up to $30^{\circ}$ Celsius. It implies that Monday is relatively hotter than other days on average, which is in line with the weekend effect in finance.

A research which examined this temperature seasonality is Forster and Solomon (2003). By using surface measurement of maximum and minimum temperatures from Global Daily Climatological Network data set, they documented that many climate stations in the world have reported high temperature level from Saturday to Monday, a similar occasion to DOWA.

Figure 2 The Frequency of the average temperature on Daily Basis
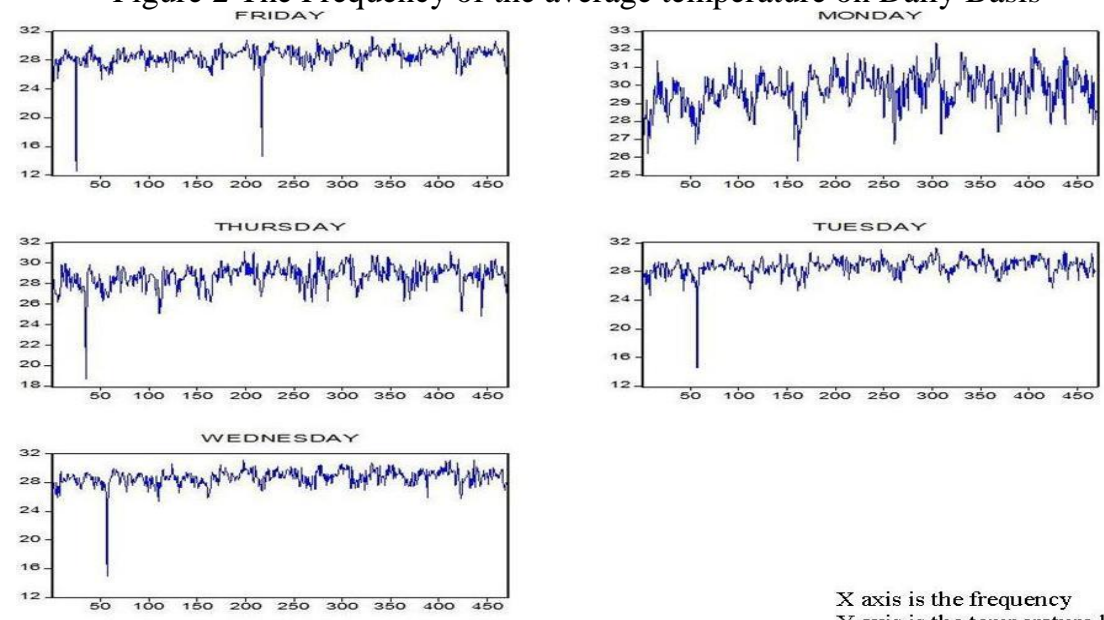

$\mathrm{X}$ axis is the frequency $\mathrm{Y}$ axis is the temberature level

Therefore, we can propose a proposition that weather has abilities to influence the irrationality of investor during Monday. The seasonality of weather on Monday and the previous empirical psychology literature about the effects of weather on human behavior can be used to hypothesize this notion. The logical justification is that the seasonality on temperature during Monday might give moods fluctuation to investors. This moods fluctuation awards an affection bias in trading decision making and DOWA is the result of the bias.

\subsection{Moon and the Monday Irrationality / DOWA}

This study proposes another affection bias as the driver of DOWA: Moon Phase. The role of moon phase on human behavior actually has been become widespread in many beliefs. These beliefs have been started since Greece or China ancient time to the present. 
Religious ceremonies in Islam, Hebrew, Jewish, or Animism are often timed to match precise phase of lunar month. As a consequence of these phenomena, psychology scholars have investigated the role of the phases on human moods.

One of psychology papers is Kane et al. (1967) study. They examined the effects of full moon phase on human behavior in regards of altering the moods to be more depressive behavior, emotional disturbance, and normal changes. Dewey (1971) addressed that maternity occurred more during waxing period than waning period. He also argued the death rate increased during full moon phase. Further, Cuningham (1979) also addressed full moon phase effects on generosity behavior in service. Other research also found the relationship between moon phase and human behavior, such as arson activity and violence (Katzeff, 1981), accident at work (Nogueira, 1982), mood fluctuation (McFarlane, 1987), anxiety and depression (Wilkinson, 1997), and quality of life (Barr, 2000).

Relate back to finance, Dichev and Janes (2003) found the role of moon phase on economics decision making. They concluded that, even though moon phase did not affect volatility and trading volume, it had effect on market returns. Yuan, Zheng, \& Zhu (2005) investigated the moon phase effects on market returns and found that the returns are lower on full moon than the days around new moon. The return difference was around 3\% to 5\% between new moon and full moon. Further, they also argued that moon cycle did not affect the volatility and trading volumes. Gao (2009) also investigated the relationship between moon phase and market return in two major Chinese stock market over 16 years, and concluded lunar phases did affect the stock returns. He/She showed the returns were relatively lower in new moon and relatively higher in full moon.

Further, our pre-investigation found that the full moon-new moon occurred more on Monday rather on other weekdays after we plotted it (see Figure 3). It implies the full moon anomaly during the period of 1999 until 2010. This is in line with the weekend anomaly in finance. Thereby, if the full moon occurred more on Monday, and full moon has contributed in human behavior, it is possible that DOWA was caused by the moon phases. Hence, we hypothetically postulate proposition: "there is a role of moon phase on investor's Monday irrationality".

Figure 3 Frequency of New Moon and Full Moon Across Day-of-the-Week

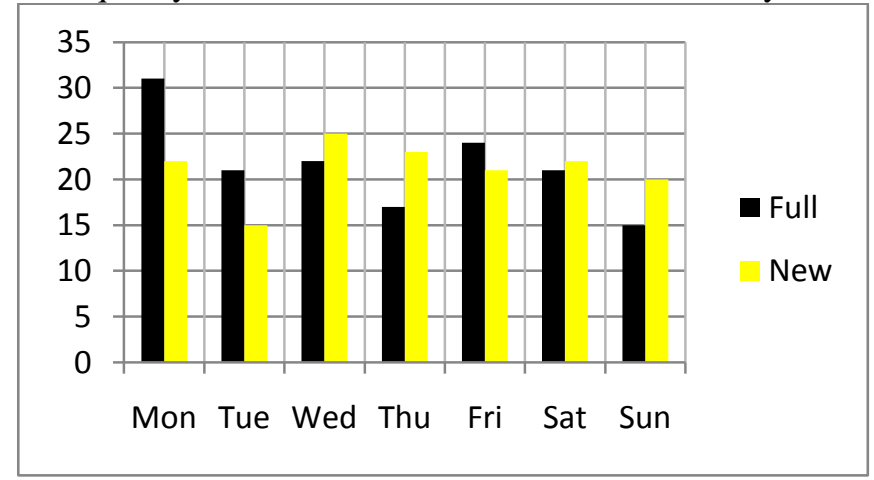

\subsection{Attention bias and the Monday Irrationality / DOWA}

In psychology literature, it is not only affection (mood) affecting human behaviour, but also cognition. This paper proposed cognition biases have a role on driving the irrationality of investor. One of the cognition biases is attention bias. Huge study has shown that people make decision in choosing based on experience (Shefrin, 2000), memory (Cloitre \& Liebowitz, 1991), anxiety (Bradley, Mogg, White, Groom, \& Bono, 1999), fear (LeDoux, 1996), and happiness (Eysenck, 1992). In psychology, they called it as attribution to attention and heuristic or "attention bias". 
Attention bias can be described as a psychological event of an individual because of the activity of the brain mechanism on the response and detection of stimulants such as threatrelated, anxiety, curiosity, and emotion (LeDoux, 1996; Fox, Russo, \& Dutto, 2002). It is a response to the availability of information that perceived by investors' cognitive experiences. Tversky and Kahneman (1973) address availability of information can influence investing judgment. They introduced the availability heuristic which an investor evaluates the events probability by availability, i.e. by the ease with which relevant instances come to mind. Further, they mentioned that the reliance on the availability heuristic leads to systematic biases.

In general, this attention bias can be caused by the sentiment and news. In terms of sentiment, Yantis (1998), and also Barber and Odean (2003) addressed the general knowledge, fear, and memory of market behaviour as the stimulants of investor attention in trading. In other words, if investors have knowledge and experience of seasonality, they will trade in the seasonality. Abraham and Ikenberry (1994), Berument and Kiymaz (2001), and Wong et al. (2006) stated that investor sentiment can be the driver of the seasonality in Monday. This is in line with the proposition in attention bias literature.

The sentiment can be caught by the magnitude of price in mimicking the liquidity. Baker and Stein (2004) explained that the liquidity might influence the investor sentiment in stock trading. Investors anticipate the market by looking at the liquidity of the single stocks. On Monday, the stocks are usually dispersed negatively and having higher level of liquidity. Having this information, investors tend to push their stock in the market as they have the signal. This attention is bought by investors, and as consequence it generated DOWA.

In terms of attention on news, several studies have shown that most of bad news was published on Monday. On average, firm announce good news during market expansion and bad news during contraction. One of the empirical findings was investigated Boyd et al. (2005). They found that, an announcement of economy events is good news for stocks during economic grows and bad news during economic reduction. Veronesi (1999) showed that bad news in good times and good news in bad time would generally be associated with increase the uncertainty, and consequently increase the attention of investors. Lang and Lundholm (2000) documented that firms released good news prior to raising capital. In other side, Aboody and Kasznik (2000) showed that the bad news were disseminated preceding the market declines. In most of the research, they showed the bad news was disseminated during Monday as the market was significantly negative compare to other weekdays. This bad news catches the investor attention because of fear-to-lose feeling. As consequence, the decision making in investing will bias due to this availability heuristic and awards the DOWA.

We develop our next hypothesis based on this information. If the sentiment and news have caused the irrationality of investor during Monday due to their threatened feeling and emotion, it is very possible that these two factors are the driver of DOWA. In other words, this attention bias can be the sine qua non of the Monday Irrationality. Therefore, our next proposition is attention bias is the one of the determinant factors of investor's Monday irrationality.

\subsection{Cognitive Dissonance and the Monday Irrationality / DOWA}

We propose another psychological bias, which is cognitive dissonance. In a simple way, cognitive dissonance can be defined as a situation where individual has a motivational drive in changing their actions by justifying and denying. To reduce the pain psychologically, investor usually adjusts their feeling about the success of historical investment choice by remembering their stock past performance as better than in the reality. Investors also can choose the strategy by remembering the seasonality in the market or following the others opinion. 
Several studies have investigated the cognitive dissonance of investors. Goetzmann and Peles (1996) is an example. They conducted a research regarding the cognitive dissonance of investor by using survey method. They found that most of the people tend to do the cognitive dissonance to please them. Akerlof and Dickens (1982) examined the relationship between cognitive dissonance and economic consequences, and found there are changes in belief and cognitive dissonance towards economic consequences due to modernization.

Herd behavior is common proxy for this cognitive dissonance. (Devenow and Welch, 1996). Herd behaviour can be defined as an event that under certain conditions most of the investors only pay attention on a subset of securities, while neglect other securities with identical exogenous characteristics (Hirshleifer, Subrahmanyam and Titman, 1994). Herd behavior is also related to timing trading behavior (see Cipriani and Guarino, 2005), which is consistent with presumption in DOWA research (Lakonishok and Maberly, 1990; Kamara, 1997; Wong et al., 2006). Lakonishok and Maberly (1990) addressed herd behavior as the explanation for the irregularities of institutional and individual trading during Friday and Monday. Kamara (1997) also addressed institution herding as the causes of the day of the week anomaly. Additionally, Wong et al. (2006) surmised that the seasonality awareness might alert the investor to follow the market.

This herd behaviour is perceived as a spotaneous behaviour by following the market sentiment. It becomes one of the popular explanations for the variability of equity returns. In simple way, as in Monday the returns are dispersed significantly, and the information of Monday effect is well and widely disseminated among investors, therefore this study propose the cognitive dissonance of investors is the factor of DOWA. Moreover, most of the news and report were released on Monday. Investors, who not yet have any information, will follow the news to reduce their guilty feeling. This situation strengthens the rationalization of our proposition.

\section{METHODOLOGY}

This study has several stages in investigating the role of psychological biases on DOWA. Firstly, we investigate the existence of DOWA by employing the French's Model (1980). After finding the dossiers of DOWA, we investigate the role of psychological biases in two ways.

First, we test it by introducing the interaction model. In this model, the relationship of the psychological biases is examined further to the extent of in which day the association is existed. The interactions of Monday and the psychological biases deliver the role of psychological biases of Monday on the DOWA.

Second, we test the association by regress it in separate day. We investigate the effects of psychological effect in each trading weekdays. If the biases are only on Monday, and not in other weekdays, we can surmise that the psychological biases drive the DOWA. As the the control variable for the model, we introduce world effect on our model.

\subsection{Day-of-the Week Model}

The purpose of running this model is to investigate the existence of DOWA. It is important to prove it because if there is no DOWA, no need to bother examining the explanations. The baseline of our DOWA model is from French's (1980). This model is commonly used in the literature. To avoid the dummy variable trap, only 4 dummy variables are included, excluding Monday, so the intercept of the model is the proxy for Monday effect:

$$
R_{t}=\alpha+\gamma_{1} d_{\text {Tue }, t}+\gamma_{2} d_{\text {Wed }, t}+\gamma_{3} d_{T h u, t}+\gamma_{4} d_{F r i, t}+\varepsilon_{t}
$$

where $R_{t}$ is KLCI compounding return series; $d_{\text {Tue,t }}, d_{\text {Wed }, t}, d_{T h u, t}, d_{F r i, t}$ are dummy for Tuesday, Wednesday, Thursday, and Friday, respectively. 


\subsection{Psychological biases on weekend anomaly: Interaction Model}

To observe whether psychological biases affect the market behaviour and its weekend anomaly, we employ a model with interactive variables using all the psychological biases. The objective is to examine whether the psychological biases not just affect the returns, but also influence the Monday returns. For robustness reason, we utilize it also on the other trading weekdays. In the end, there will be 5 empirical models: Monday interaction, Tuesday interaction, Wednesday interaction, Thursday interaction, and Friday interaction. We will conclude and accept our proposition if the interaction only occurs on Monday and not on other weekdays.

The Model (1), given by:

$$
\begin{aligned}
R_{t}= & \beta_{0}+\left(1+d_{D}\right) *\left(\beta_{1} \text { Temp }_{t}+\beta_{2} \text { DMoon }_{t}+\beta_{3} \text { AttSent }_{t}+\beta_{4} \text { Herd }_{t}+\beta_{5} \text { Bad }_{t}\right)+ \\
& \beta_{6} \text { World }_{t}+\varepsilon_{t}
\end{aligned}
$$

where $\mathrm{D}=$ (Monday, Tuesday, Wednesday, Thursday, Friday), so $R_{D, t}$ is the KLCI returns; Temp is the weather condition in Celsius, DMoon is the moon dummy; ATG is the attention grabbing value; SD is the herding value; $d_{D, t}$ is the dummy variable of D day; we test separately the dummy interaction by changing the D to Monday, Tuesday, Wednesday, Thursday, and Friday, consecutively.

In our research, we perform additional checks to examine the robustness of our results. Our results might be prone to impact of the mis-specification errors. Therefore, this research controls the equation by introducing the world market returns as a proxy of world effect. The data is taken from Thomson World Market Stock returns.

\subsection{Psychological biases on weekend anomaly: Regression in Separate Day}

As a robustness check, we use an alternative regression approach to strengthen our findings. We pull out one-day returns of the same week-of-the-day observations from KLCI returns (for example is taking Monday returns only or Tuesday returns only). Therefore, we constructed 5 different KLCI return series, from Monday to Friday.

The purpose of this model is to investigate further whether the role of psychological biases does exist on Monday only. This model should confirm our dummy interaction model, whereas there will be no significant relationship between psychological biases and the returns of other weekdays (Tuesday, Wednesday, Thursday, and Friday). The model is as follow.

$$
\begin{aligned}
R_{D}= & \beta_{0}+\beta_{1} \text { Temp }_{D}+\beta_{2} \text { DMoon }_{D}+\beta_{3} \text { AttSent }_{D}+\beta_{4} \text { Herd }_{D}+\beta_{5} \text { Bad }_{D}+ \\
& \beta_{6} \text { World }_{d}+\varepsilon_{d}
\end{aligned}
$$

where the $D$ is the day the week from Monday to Friday, so there are 5 equations to be estimated. This approach allows us to examine the influence of the psychological biases on the specific week-of-the-day series.

\subsection{Psychological biases on weekend anomaly: Size-Based Portfolio Analysis}

We further examine the Model (3) using firm portfolio constructed based on size (market values). We constructed a total of 10 size portfolios, so for Model (3), there are 50 equations to be estimated each models. Portfolio 1 comprises of the smallest market capitalization firms and Portfolio 10 contains the largest market capitalization firms. The purpose of this size formation is to catch which investor has been affected by the psychological biases. Because in literature, we found most of institution investor does stock trading on big cap, meanwhile retail investor does stock trading on small cap. It is generally known that most of retail investors are less rational and less informed than the institutional investor. Note that more 
than $80 \%$ of Malaysian stock exchange investors are retail investors. Therefore, this sizebased portfolio analysis is a good way to investigate the role of psychological biases on different type of investors.

\subsection{Data}

In investigating the role of psychological biases on the DOWA, we assume the secondary data is fit and robust enough as the proxy of the behavior. This study retrieved the data from four reliable sources, which are: DataStream (for stock market information), Malaysian Stock Exchange (for the news announcement), Malaysia meteorology office (for temperature data), and www.moonconnection.com ${ }^{2}$ (for the moon phase calendar). The longest period for which we have these data available is 1 January 1999 until 22 March 2010.

For the temperature level data, we calculate differently from prior research, such as Saunders (1993), Kramer and Runde (1997), and Jacobsen and Marqueiring (2004). The sample was taken from maximum temperature and minimum temperature average values of all Malaysia climate stations. This paper used the average of the lowest temperature and the highest temperature in the same day. Furthermore, we took it in daily basis not monthly or annual data like the previous research. In the end, we average the minimum and maximum temperature to get our measure for temperature, as below:

$$
\begin{gathered}
\text { Temp }=\frac{\text { Temp } p_{\text {min }, t}+\text { Temp } p_{\text {max }, t}}{2} \\
\text { where Temp } p_{\text {min }, t}=\frac{\sum \text { min Temp of stations }}{\text { number of station }} \text { and Temp } p_{\text {max }, t}=\frac{\sum \text { max Temp of stations }}{\text { number of station }}
\end{gathered}
$$

The moon phase measure is a dummy variable. We limit the moon phase into 2 phases, which are: new moon and full moon. Based on the astronomy and previous literature in psychology, the effect of full moon is last for 2-3 days. Therefore, this research put the full moon dummy on the day before the "peak" full moon, the peak of full moon, and the day after the peak full moon. In short, we give dummy value of one $(D M o o n=1)$ for full moon phase.

For the proxy of attention bias, we took the sentiment of investor ${ }^{3}$ on the magnitude of price changes and the news as the measures. We assume that the magnitude of the price can capture the sentiment of attention-driven of investor. Thereby, we modified Barber and Odean (1998) model from volume based to liquidity based. It is in line with Baker and Stein (2004) where the attention can be capture from the sentiment of investor from the liquidity. The model is as follow.

$$
\text { Attention Sentiment }=\frac{(\text { clo } \sin g \text { Price }- \text { Bid Price })-(\text { Clo } \sin g \text { Price }- \text { Ask Price })}{(\text { clo } \sin g \text { Price }- \text { Bid Price })+(\text { Clo } \sin g \text { Price }- \text { Ask Price })}
$$

Meanwhile, the reaction on the news is built on dummy variables. We put 1 if there is a bad news (DNews $=1)$. The criteria of bad news is (a) announcement of decreasing profit, (b) announcement of disclaimer or adverse audit opinion, (c) announcement of suspended or delisted stock, and (d) announcement of negative economy activities.

Lastly, our herd behavior model of the cognitive dissonance is constructed under Christie and Huang (1995) model where it has to assemble the dispersion measurement. This model was built based on the rational asset pricing model. The dispersion from the rational asset pricing indicates the herd formation on the industry. The logic is that during the anomalous condition, rational asset pricing models predict that large changes in the distribution of market returns would translate into an increase in the dispersion. It is because of the firm returns which hold by investors differ in their sensitivity to the market returns (Christie and

\footnotetext{
${ }^{2}$ Most of seminal papers of Moon Research use this website or www.moonconnection.com.

${ }^{3}$ We gratefully acknowledge the comment and input from Prof. Terrence Odean
} 
Huang, 1995). In other words, the tails of the normal distribution of market returns by the firms' returns indicate the herd behavior. The dispersion can be measured by the following expression:

$$
S D=\sqrt{\frac{\sum_{i=1}^{n}\left(r_{i}-\bar{r}\right)^{2}}{n-1}}
$$

where $S D$ is the daily cross sectional dispersion (standard diviation) measure, $\mathrm{r}_{\mathrm{i}}$ is the observed return of firm $i$ and $\bar{r}$ is the cross-sectional average of the n returns in the portfolio. This measure can be regarded as a proxy to individual security return dispersion around the market average. Christie and Huang (1995) suggested that the presence of herding is most likely to occur during the periods of extreme movements as they would most likely tend to go with the market consensus during such periods.

\section{Results}

\subsection{Evidence of Weekend Anomaly}

Table 1 depicts the estimates of Model (1). The coefficient of the model, which is the proxy of DOWA, is found significant in $1 \%$ level. Meanwhile, there are all significant in other days. The significant sign $(p<1 \%)$ on other day dummies indicates their returns significantly different from Monday. These findings confirm the weekend effect in Malaysian over the period of 1999 to 2010. Based on this result, we can proceed to the next procedure to investigate whether psychological factors are the drivers of DOWA.

\section{[Insert Table 1 here]}

\subsection{Psychological biases and weekend anomaly}

Table 2 documents the regression result of the equation 2. In overall, the results show that the psychological biases have significant relationship to the market returns. These associations were found on the entire of weekdays. It implies there is effect of those psychological biases on the market.

The negative sign on moon phase implies that during full moon, the market is rather to be bearish than to be bullish. In terms of weather, the positive coefficient indicates that when the temperature is higher, the market tend to be bullish. This could be due to aggressiveness of investors which bringing them to violates their utility function or, in other words, mood disorder causing them to act irrationally. In a short, our findings addressed affection bias as one of the drivers of the markets. This bias engenders a disorder of emotion and mood of investor. The consequence is investor does trading by following their mood instead of their utility function; a violation of rational assumption behavior. Hence, our findings are consistent with Saunders (1993), and Brahmana, Hooy, and Ahmad (2011a) who demonstred the evidence of the relationship between Weather and Market; and Yuan, Zheng, Zhu (2006) who addressed the relationship between Moon and the market.

Meanwhile, in terms of cognition bias (attention, and cognitive dissonance), we found the significant association of attention bias, and cognitive dissonance on the market returns. This finding informs that the investor has no information in trading and follows their heuristic bias. This could be happened as investor face a problem or experience asymmetric information. In addition, investor also may trap on their availability bias as the trade through the bad news. This is in line with Odean (1999), and Yu and Hsieh (2010) who found a relationship between attention of investor and market. 
Our herd behaviors put the picture that investor are having regret aversion or cognitive dissonance. Investor follows other investor that they believed more sophisticated and it has influenced on the market. This herd behavior has been done as self-justification of investor in making excuses of the future bad decision. Our findings are consistent with Christie and Huang (1995), and Hwang and Salmon (2004) who found the evidence of herd behavior on the market.

The important of table 2 is the evidence of the relationship between psychological biases and weekend anomaly. In examining whether the psychological biases are the factors for weekend anomaly, we include the interaction dummy of each day started from Monday up to Friday. If the relationship has occurred only in Monday, we can surmise that psychological bias has effect on investor irrationality and cause DOWA. The dummy interaction between the regressor and day dummy can reveal whether the relationship between the psychological biases and market only occurs on that certain day. It reports the psychological biases are the factors in driving the weekend anomaly.

Table 2 depicts the psychological biases interaction with the Monday is the only interaction that has significant relationship to the market. This significant relationship cannot be found on other weekdays. In other words, when the market was influenced by the psychological biases, and this influence occurred only during Monday. The biases have influence the investor decision making in investment on Monday only. It implies these biases are the determinants of the weekend anomaly.

\section{[Insert Table 2 here]}

In table 2 of Monday, the temperature, moon, sentiment, and bad news have significant relationship to the market, but not the herd behaviour. The interactions of Monday with temperature, and also with bad news are significant in $10 \%$ level. Meanwhile, the interactions of Monday with the moon phase, and with the sentiment are significant in $1 \%$ level. Interestingly, even though the herd behaviour was found significantly associated to the market, but the interaction variable show it not significant. The latter, herd behaviour interaction will be the one and only variable that has not significant association with the market in each trading weekdays.

For Tuesday, we can see the same independent variables (weather, moon, sentiment, bad news, and herd behaviour) are significantly related to the market. The interaction dummy between Tuesday and the psychological biases have been found to be not significant to the market. It strengthens our hypothesis that those biases only affect the irrationality of investor on Monday.

Similarly, Wednesday psychological biases also have no significant relationship to the market. The dummy interaction p-value is found to be not less than $10 \%$ significant level. This situation also strengthens our hypothesis, that the psychological biases have no effects on other days except Monday.

Our other 2 trading weekdays: Thursday and Friday, show the same conclusion with Tuesday and Wednesday whereas we did not find any relationship between the dummy interaction and the market; even though the psychological biases have a significant relationship with the market. It implies the psychological biases effects did not occur in these weekdays, except on Monday.

Based on these findings, we can conclude that the psychological biases are the sine qua non of DOWA. The weather, full moon, and attention bias of investor on Monday have influenced the trading style of investor on Monday by disturbing its irrationality. We state this conclusion because even though there is a relationship between psychological biases and market, the relationship actually only occurred on Monday, not other days. It means the psychological biases of investor during their investing decision have created the irrationality on Monday. As the consequence, the market went to anomalous condition where the Monday 
returns were significantly dispersed compare to other weekdays. The temperature level, moon phase, sentiment of investor, and reference on bad news are the factors in making this anomaly. Hence, our study empirically found that trading behaviour of investor on Monday is the reason of weekend anomaly. It is in line with the suggestion of previous research of weekend anomaly such as Abrahaham and Ikenberry (1994), Clare et al. (1995), Berument and Kiymaz (2001), Wong et al. (2006), and Yahyazadehfar (2006).

Note that the R-Squared of the equation model on these trading days is also decreasing. For instance, Monday adjusted R-Squared is $6.4 \%$ but the other days are 5\% in average. It implies the psychological biases on Monday can explain the model much better compare on other days.

\subsection{Regression with separate day series}

We further investigate the role of psychological biases on DOWA by employing the alternative approach. Given that the psychological biases and the interaction with Monday dummy have effects on market returns, we investigate further in detail day-by-day whether our independent variables are the factors of DOWA. Some may argue that the interaction dummy might contain the effect of the regressor. This separate day-of-the-week model (equation 3) gives clearer picture of the trading behaviour during Monday.

Table 3 reports the R-square of Monday model is notably higher from other weekdays. Monday r-square is up to $12 \%$, meanwhile the other weekdays model is only $1.7 \%$ average. It implies the psychological biases can explain the Monday returns much better than in other days; an indication of the role of psychological biases on weekend anomaly.

Our Monday returns model shows that the whole set of psychological biases have the significant association. These are perhaps the most striking results. It confirms the significance association summarized in table 2 where Temperature level, moon phase, herd behaviour, sentiment, and bad news were significantly influenced the Monday returns in $1 \%$ level. This result implies these psychological factors are the determinants for the weekend anomaly.

To confirm our conclusion, we tested the model again in other weekdays. In term of Tuesday model, we found it interesting. The affection biases (temperature and moon phase) are the factors for the Tuesday returns. Table 3 paints a very different picture about how the world effect is. Instead of having the association with the world, like other days, the Tuesday returns do not have the world effect.

As depicted in Table 3, the Wednesday model shows the moon effects on the returns in $5 \%$ significant level. This moon effect is the only psychological biases that influence the market. Meanwhile, the temperature level, herd behaviour, sentiment, and bad news were not found in the Wednesday's results. It is in line with our proposition that the psychological biases only affect the Monday returns.

Further, the Thursday model surmises that no psychological effect except the moon effect. It is the same conclusion as the Wednesday model. There is no effect of temperature, herd behaviour, sentiment, and bad news found. Hence, it confirms our purpose of this robustness check that those psychological biases just affected the Monday returns.

Lastly, the Friday model shows a linear result with Forster and Solomon (2003). They found the anomaly of the weather where the temperatures on Saturday until Monday are significantly higher compare to other days. Friday is the starting point of this weather anomaly. Therefore, it is not surprising to see the association result between temperature and Friday returns. Yet, it is still not rejecting our proposition regarding the psychological biases are the sine qua non of weekend anomaly. 


\section{[Insert Table 3 here]}

This result has strengthened our conclusion whereas the psychological biases are the sine qua non of DOWA. The affection bias from temperature level and moon phase on Monday has influenced the irrationality of investor, and generates the weekend anomaly. It is in line with our pre-findings of the temperature anomaly and number of occurrences of full moon on Monday. These occasions have brought an impact to investor's rationality in making decision. It has given the mood disorder and in the end done randomized mode trading. This is why the returns on Monday are highly dispersed compare to other days.

In terms of cognition bias from sentiment, heuristic, and cognitive dissonance, we also found those cognitive biases have significant relationship to the market. The effects of these biases were occurred on Monday only, not on other weekdays. It means on the first trading day (Monday), investor tends to have biases as they did not have any suave information. Investors have responded to certain information due to this "no information" condition. If they found the price of the stocks was closed above its 52-week highest price, they tended to sell it as they have sentiment biases. If they found a bad news on Monday, they tend to react improperly to the market. If they found the big institution or the market tended to sell on Monday, these investors also have a tendency to sell it following the market maker. This behaviour is caused by the availability bias and cognitive dissonance. Investors follow their irrationality as they are reference dependence to a bad news or they are trying to justify their "guilty" feeling. Unfortunately, Most of bad news, or market sentiments, or even the market behaviour reaction was arisen during Monday. This occasion generates the biases in decision making and constructs the weekend anomaly.

Thus, after receiving proper information on other days, they stopped following their cognitive biases, except for herd behaviour. The herd behaviour has still kept happening until Tuesday. This situation implies that investor might wait until Tuesday to gather a suave information for the trading. This explains why there is no significant relationship between cognitive dissonance and market on other days.

In a nutshell, the psychological biases have effects on investor irrationality and caused DOWA. Table 3 confirms our hypothesis where weather, moon, sentiment bias, bad news, and herd behaviour are significantly related to market. This relationship, except the moon, can be found only on Monday not other days. It is in line with our Model (2) results. Therefore, we surmise that these three psychological biases as the factors that drive the DOWA.

\subsection{The size-based portfolio results: Monday Returns model}

The same regression model (equation 3) were run but in different data set of dependent variables. Table 2 and Table 3 are the results of the regression in market index returns. Meanwhile, Table4 and Table5 report the result of the regression in using portfolio returns as the dependent variables.

The rationalization beyond this robustness check is to examine whether the effect of psychological biases depends on the size. It is noteworthy that institutional investors are more to big caps, meanwhile retail investors are more to small caps. Further, institutional investors are more rational and non-asymmetric bias compare to retail investor. Thereby, this sizebased portfolio formation can reveal whether the psychological biases are only experienced by retail investor or institution investor or maybe both. This is our justification in regards with size portfolio formation.

We define portfolio 1 and portfolio 2 as the small-size portfolio formation. The mediumsize portfolio is from portfolio 3 until portfolio 8. Meanwhile, portfolio 9 and portfolio 10 are defined as the big-size portfolio formation. Portfolio 1 is assumed as the very small portfolio 
that only bought by retail investors. In other hand, portfolio 10 is assumed as the very by portfolio that only bought by institutional investors.

Depicted in Table 4, the temperature effect has occurred in medium size portfolio formation. Portfolio 7 has the probability value around $1 \%$. Portfolio 3 and 5 also experienced the temperature effect with the probability value lower than 5\%. Portfolio 4 and 6 also undergo the weather-induced mood disorder with an acceptance in $10 \%$ significant level. Interestingly, we found one big-size portfolio falls on the temperature effect, but with the probability value $8.3 \%(p=0.0833)$. Thus, we did not find any effect of temperature on other big-size portfolio formations. In short, we surmise that the temperature effect only causes the weekend anomaly on medium size but not on small or big size stocks.

With regards to moon effect results, this research surprisingly discovers the role of moon-induced mood disorder on the whole set of portfolio. From portfolio 1 (very small size) to portfolio 10 (very big size) have experienced the impact of moon in generating the weekend anomaly with $1 \%$ significant level. In other words, the moon disorder did not influence only the retail investors but also the institutional investor. This is logic $80 \%$ of human body is water, the gravity of moon can change investor mood. Simply to conclude, the moon phase is the determinant for the weekend anomaly for both retail investors and institutional investors.

Meanwhile, the herd behaviour was found on middle-size portfolio. Portfolio 7 shows a significant effect of cognitive dissonance in 1\% level. Meanwhile, portfolio 5 and portfolio 6 were found having significant association in 5\% level. However, the herd behaviour does not exist on small or big size formation. As a conclusion, we can surmise the weekend anomaly in this middle size portfolio was determined by the herd behaviour.

Similar to temperature effect results, this research found that attention sentiment has influenced the investor decision on Monday, especially those who bought middle-size size portfolio formation. We found the portfolio 5 and portfolio 8 have the attention sentiment as the driver of the weekend anomaly. The association is significant in $1 \%$ level. Meanwhile, the attention sentiment was also found in portfolio 3 and portfolio 7 in the $10 \%$ significant level. It implies the attention sentiment renders the Monday irrationality only on middle size portfolio. The small size and big size were not encountered this bias.

Another psychological bias, attention to bad news, is slightly different from the results of other psychological biases. We found the very small size portfolio or portfolio 1 experienced the bad news in $10 \%$ significant level. It is logic as retail investors are susceptible to fear feeling. The incoming bad news can create the bias in decision making for them. As much bad news occurred on Monday, it is not surprising to see this result. Except the portfolio 1, there are two other portfolio formation that underwent to the bad news as the driver of Monday irrationality. Portfolio 5 and portfolio 7 show us that bad news also the determinants of DOWA for middle size portfolio.

\section{[Insert Table 4 here]}

Based on the results on Table 4, we found several interesting findings on our portfolio formation. Portfolio 5 was found as the only portfolio formation that experienced almost all the psychological biases as the determinant for weekend anomaly. In other words, the psychological biases, affection and cognition, are the sine qua non of weekend anomaly in middle size portfolio. Moreover, all middle size portfolio (portfolio 3 until portfolio 8) have undergone the affection biases (temperature and moon) as the driver for the weekend anomaly. In simple English, the temperature and moon phase are the factors of the weekend anomaly for middle size anomaly. Thus, in term of cognition biases such as attention and cognitive dissonance, the results vary. 
Portfolio 10 or the very big size formation is the only big size formation that affected by affection biases. Meaning that institutional investors, even though they are cognitively rational, but still susceptible to mood disorder that caused by temperature and moon.

Portfolio 2 and Portfolio 9 are the only formation that did not have any psychological factors as the determinant of weekend anomaly, except the moon phase. Note that these two formations are clustered on small size and big size formation. However, the psychological biases, especially the cognitive biases, did not play important role on the making of weekend anomaly. The only cause of weekend anomaly in these formations is the moon phase.

\section{[Insert Table 5 here]}

Table 5 presents a confirmation of the goodness of our results. You can see from the table that most of psychological biases had not play important role in the other days. It indicates these psychological biases generated only the Monday irrationality. For instance is the temperature effect. In table 4, we showed that middle size portfolio and very big size portfolio have experienced the temperature effect on Monday. Table 5 seems to confirm our proposition whereas it does not depict any sign of temperature on other weekdays. It means we can conclude that temperature level is the factor for the weekend anomaly. The anomaly in the weather has caused the irrationality of investor on Monday as the Monday temperature is averagely warmer than other weekdays.

Similar results also for the moon effect. Table 4 depicted that all portfolios were undergone to the moon effect on Monday. It implies the moon as the factors for weekend anomaly. Table 5 confirms it by showing that the moon effect only occurred on portfolio 8 and only on Wednesday in 10\% significant level. The occurrences of full moon on Monday have give impact to investors and causing the weekend anomaly. We can surmise that there is indeed a moon effect on making the Monday irrationality.

Previously, table 4 shows that herd behaviour causes the Monday returns on middle size portfolio. However, table 5 shows us that no herd behaviour on other days. It is the same as the temperature level. Hence, we can surmise that herd behaviour is the one of the factors of the weekend anomaly. As there is no suave information on Monday, investors follow the others to justify their guilty feeling. Table 4 and Table 5 just confirm it.

Meanwhile, the attention sentiment is interestingly occurred in Wednesday only, and through most of the formations. Table 5 portrays the sentiment is not only undergone on Monday returns but also on Wednesday. It is hard to conclude that attention sentiment is the factors of weekend anomaly.

Lastly, our bad news variable shows promising results. As earlier mentioned, most of the bad news were announced on Monday. Hence, it is logic to see these results. Table 4 stated that bad news was the trigger of weekend anomaly for small size and medium size portfolio. Table 5 confirms it by showing no bad news effect on other days, on other portfolio formations. Thereby, we can conclude that bad news is also the factor of the weekend anomaly. It affects the small and medium stocks and takes part in making the anomalous condition on Monday.

\subsection{World effect}

Introducing the world returns as the control variables, our results surprisingly found an interesting dossier. In the market integration study, the world has a significant effect on local stock markets, especially the emerging one. The tables in our paper showed it differently.

The world stock market effect occurred on all weekdays except Tuesday. It implies the effect of the world onto the market happened through the weekdays, but it missed Tuesday. In other words, the world did not give any effect to Malaysian stock market during Tuesday. Further, the effect of the world was just on middle size portfolio, not on small size neither big size. In short, the world stock market just gave impact on the middle size portfolio during 
weekdays, except on Tuesday. On the Tuesday, neither small size, medium size, nor big size of firms in Malaysia stock market has a significant effect of the world.

\section{Conclusion}

Much research in DOWA suggested trading behaviour as the explanation of investor irrationality. However, none of them have empirically investigated it. Motivated by psychological approach, this paper fills to the anomalies literature by exploring the determinants of the irrational and anomalous condition in market. We test whether the psychological biases including affection bias (Weather and Moon Phase), attention bias, heuristic biases, and cognitive dissonance (herd behavior) are the potential factors determining the DOWA.

Using French's (1980) model, we found that the Malaysian stock market has experience the weekend effect. Then we continued to test the relationship in two ways: (1) daily interaction model, and (2) separate day-of-the week model. For robustness check we also repeat the analyses on 10 sized-based firm portfolios.

Because our result showed the significant relationship between psychological biases and stock markets, it may surprise some finance scholars in terms of the apparent inconsistency with rationality behaviour. Moreover, a more sophisticated view of the role of affection and cognition in human decision can reconcile any unsolved problem in DOWA. It confirms by our interaction and alternative model where the psychological biases were significantly associated to Monday returns only. Our robustness check by using portfolio returns also showed the similar results.

The results of this research imply that human is sensitive to a stimulant. It gives a bias decision through affecting the human psychology. In terms of affection, Weather and moon can give an intuitive judgment to investors because they follow their mood. When weather and moon occurrences are highly on Monday compare to other days, it will lead investor to have a mood disorder on Monday. As a consequence it has brought mood disorder on Monday and guided investor to irrationality. Their intuitive trading "rules" are based on the associations on information that are formed on a subconscious level where our findings proved this hypothetical question. Testing it statistically, we found there is indeed Weather and Moon phase effect on Monday returns.

In terms of cognition bias, we found the attention sentiment, availability bias, and herd behaviour have also important role on DOWA. Those biases are the factors that made the irrationality of investors. As Monday is the first trading day, investor has these biases to overcome their fearsome in losing money. They also made self-justification by following the market flow during Monday to reduce the regret feeling (or in psychology it called as blame sharing). Moreover, as bad news occurs more on Monday, it stimulates the fear of investors in trading. The stimulants such as bias information, market movement, 52-weeks high price spread, bad news, recommendation of better equity researcher, brings a bias to investors. They do not have any fresh information and good direction in stock trading. These events stimulate the cognition of investors in making decision. The outcome is the irrationality on Monday and as a result, it generates DOWA.

Perhaps the most promising avenue for further research is the implications this model has for psychology experimental research. Most of behavioural research has not proved the existence of time preference bias of investors. As it is out of scope of our research, further research has to investigate this time preference bias empirically by adopting hyperbolic discounting model to confirm our results. If it is found there is time preference bias, it will be a huge finding for finance whereas actually rational behaviour cannot be hold and beating the 
market is a matter of psychological issue. In a short, future research might examine the time preference bias empirically in longitudinal matter. Another interesting issue for future research is to find the psychological stock, not in industrial level, but truly in firm level.

\section{References}

Abraham, A. and D.L. Ikenberry, (1994) The Individual Investor and the Weekend Effect. The Journal of Financial and Quantitative Analysis, 29(2): p. 263-277.

Agrawal, A. and K. Tandon, (1994) Anomalies or Illusions? Evidence from stock markets in eighteen countries. Journal of International Money and Finance, 13: p. 83-106.

Akerlof, G.A. and W.T. Dickens, (1982) The Economic Consequences of Cognitive Dissonance. The American Economic Review, 72(3): p. 307-319.

Baker, H.K. and J.R. Nofsinger, (2002) Psychological Biases of Investor. Financial Services Review, 11: p. 97116.

Banerjee, Abhijit, V. (1992) A SimpleModel of Herd Behavior. The Quarterly Journal of Economics, 107(3), pp. $797-817$

Barber, B.M. and T. Odean, (2007) All That Glitters: The Effect of Attention and News on the Buying Behavior of Individual and Institutional Investors. The Review of Financial Studies.

Barr, W., (2000) Lunar Revisited: The Influence of the moon on mental health and quality of life. Journal Psychosocial Nurse Mental Health Serice 38(5): 28-35

Berument, H. and H. Kiymaz, (2001) The Day of the Week Effect on Stock Market Volatility. Journal of Economics and Finance, 25(2): p. 181-193.

Brahmana, R., Hooy, C.W., and Ahmad, Z (2011a). Weather, Investor Irrationality and Day of the Week Anomaly: Case of Indonesia. Upcoming edition of Journal of Bioeconomics. http://www.springerlink.com/content/a281223889057611/

Cao, M., \& Wei, Jason. (2005). Stock market returns: A note on temperature anomaly. Journal of Banking \& Finance, 29:1559-1573.

Christie, W.G., Huang, R. D., 1995. Following the Pied Piper: Do individual Returns Herd

around the Market? Financial Analyst Journal, July-August 1995, 31-37

Clare, A.D., Z. Psaradakis, and S.H. Thomas, (1995) An Analysis of Seasonality in the U.K. Equity Market. The Economic Journal, 105(429): p. 398-409.

Cloitre, M. and M.R. Liebowitz, (1991) Memory Bias in Panic Disorder: An Investigation of the Cognitive Avoidance Hypothesis. Cognitive Therapy and Research, 15(5): p. 371-386.

Cunningham, M.R., 1979. Weather, mood and helping behavior: Quasi-experiment with the sunshine samaritan. Journal of Personality and Social Psychology 37: 1947-1956.

Devenow, A., Welch, I., 1996. Rational Herding in Financial Economics. European Economic Review 40, $603-615$

Dewey, Edward R. 1971. Cycles: The mysterious forces that trigger events. Foundation for the Study of Cycles, New York.

Dichev, I.D., Janes, T.D., 2003. Lunar cycle effects in stock returns. Journal of Private Equity 6 (Fall): 8 -29.

Dimson, E. and P. Marsh, (2001) U.K. Financial Market Returns, 1955-2000. The Journal of Business, 2001. 74(1): p. 1-31.

Duasa, J. and S. Kassim, (2009) Herd Behavior in Malaysia Capital Market: An Empirical Analysis. Journal of Applied Economic Sciences, 4(1): p. 45-57.

Dubois, M. and P. Louvet, (1996) The day-of-the-week effect: The international evidence. Journal of Banking and Finance, 20: p. 1463-1489.

Ellis, A., (1991) THE REVISED ABC's of Rational-Emotive Therapy. Journal of Rational-Emotive \& Cognitive-Behavior Therapy, 9(3): p. 139-172.

Forster, P.M.d.F. and S. Solomon, (2003) Observations of a "Weekend Effect" in Diurnal Temperature Range. Proceedings of the National Academy of Sciences of the United States of America, 100(2): p. 11225-11230. 
Fox, E., R. Russo, and K. Dutto, (2002) Attentional bias for threat: Evidence for delayed disengagement from emotional faces. Cognition \& Emotion, 16(3): p. 355-379.

French, K.R., (1980) Stock Returns and The Weekend Effect. Journal of Financial Economics, 8: p. 55-69.

French, K. and R. Roll, 1986, Stock return variances: The arrival of information and the reaction of traders Journal of Financial Economics 17, 5-26

Gao, Q. (2009) Lunar Phases Effect in Chinese Stock Returns. 2009 International Conference on Business Intelligence and Financial Engineering. Beijing, China July 24-July 26

Herbst, A. (2007) Lunacy in the Stock Market-What is the Evidence? Journal of Bioeconomics (2007) 9:1-18

Hirshleifer, D. (2001) Investor Psychology and Asset Pricing. The Journal of Finance, Vol. 56, No. 4, Papers and Proceedings of the Sixty-First Annual Meeting of the American Finance Association, New Orleans, Louisiana, January 5-7, 2001, pp. 1533-1597.

Hirshleifer, D., and Shumway, T. (2003) Good Day Sunshine: Stock Returns and the Weather. The Journal of Finance, Vol. 58, No. 3. (Jun., 2003), pp. 1009-1032.

Howarth, E. and Hoffman, M. S. (1984). A Multidimensional Approach to the Relationship between Mood and Weather. British Journal of Psychology, 75(February): 15-23.

Hsieh, S.-F. (2010) The Effect of Attention on Buying Behavior during a Financial Crisis: Evidence from the Taiwan Stock Exchange. in Malaysia Finance Association Conference. Sunway, Selangor, Malaysia: MFA.

Isen, Alice., Shalker, Thomas, E., Clark, M., and Karp, L.(1978) Affect, accessibility of material in memory and behavior: A cognitive loop? Journal of Personality and Social Psychology 36: 1-12.

Jaffe, J. and R. Westerfield, (1985) The Week-End Effect in Common Stock Returns: The International Evidence. The Journal of Finance, 40(2): p. 433-454.

Johnson, Eric J., and Amos Tversky. (1983) Affect, generalization, and the perception of risk, Journal of Personality and Social Psychology 45, 20-31.

Kamara, A., (1997) New Evidence on the Monday Seasonal in Stock Returns. The Journal of Business, 70(1): p. 63-84.

Kamstra, Mark J., Lisa A. Kramer, and Maurice D. Levi, (2000) Winter blues: Seasonal Affective Disorder (SAD), the January effect, and stock market returns, Working paper, Faculty of Katzeff, K., 1981. Moon Madness. Citadel Press, Secaucus, N.J.Commerce, University of British Columbia.

Krämer, Walter., Runde, Ralf. (1997). Stocks and the Weather: An Exercise in Data Mining or Yet Another Capital Market Anomaly?. Empirical Economics (1997) 22:637-641

Lakonishok, J. and S. Smidt, (1988) Are Seasonal Anomalies Real? A Ninety-Year Perspective. The Review of Financial Studies, 1(4): p. 403-425.

Lakonishok, J. and E. Maberly, (1990) The Weekend Effect: Trading Patterns of Individual and Institutional Investors. The Journal of Finance, 45(1): p. 231-243.

Lakonishok, Josef, Andrei Shleifer, \& Robert W. Vishny. (1994) Contrarian Investment, Extrapolation, and Risk. The Journal of Finance, 49(5), pp. 1541-1578

Linnainmaa, J., (2003) Who Makes the Limit Order Book? Implications for Contrarian Strategies, AttentionGrabbing Hypothesis, and the Disposition Effect.

Lo, Andre, W., and Repin, Dimitry, V. (2001) The Psychophysiology of Real Time Financial Risk Processiong. Sloan Working Paper 4223.01, MIT Sloan School of Management.

Loewenstein, G.F., 2000. Emotion in economic theory and economic behavior. American Economic Review 65: $426-432$.

Loomes, G., \& Sugden, Robert. (1982) Regret Theory: An alternative theory of rational choice under uncertainty. The economic journal, No.92, pp.805-24

Nogueira, D.P., (1982) Effect of lunar cycle on human behaviour. Journal Royal Social Medicine, 75(9): 753754

Norem, Julie, K., \& Illingworth, K.S. Shaun. (1999) Mood and performance among defensive pessimists and strategic optimist. Organizational Behavior and Human Decision Process, Vo 79 (1), pp. 56-77

Noon, Georgia. (1978) On Suicide. Journal of the history of Ideas, Vol. 39 (3), pp. 371-386

Nofsinger, J.R. and R.W. Sias, (1999) Herding and Feedback Trading by Institutional and Individual Investors. The Journal of Finance, 54(6): p. 2263-2295.

Odean, T., (1998) Are Investors Reluctant to Realize Their Losses? The Journal of Finance, 53(5): p. 17751798.

Pardo, Angel, \& Valor, Enric. (2003). Spanish Stock Returns: Where is the Weather Effect?, European Financial Management, 9(1): 117-126.

Ranguelova, E., (2001) New Evidence on Individual Investor Trading Activity, in Harvard Series.

Rezvanian, R., R. Turk, and S. Mehdian, (2008) Anomalous Behavior in Security Market: Evidence from Equity Markets of the People's Republic of China.

Saunders, Jr, Edward M., (1993) Stock Prices and Wall Street Weather. The American Economic Review, Vol. 83, No. 5. (Dec., 1993), pp. 1337-1345. 
Scharfstein, D., Stein, J., 1990. Herd Behavior and Investment. American Economic Review 80,465-479

Schwarz, Norbert. (1990) Feelings as information. Informational and motivational functions of affective states, in R. Sorrentino, and E.T. Higgins, eds.: Handbook of Motivation and Cognition (Guilford Press, NewYork).

Schwert, G.W., (2002) Anomalies and Market Efficiency, in Handbook of the Economics of Finance, G. Constantinides, M. Harris, and R.M. Stulz, Editors. North-Holland Publishing Company.

Shefrin, H. and M. Statman, (1985) The Disposition to Sell Winners Too Early and Ride Losers Too Long: Theory and Evidence. The Journal of Finance, 40(3): p. 777-790.

Shefrin, Hersh. (2000) Beyond Greed and Fear: Understanding Behavioral Finance and the Psychology of Investing. Financial Management Association Survey and Synthesis Series. Boston, MA: Harvard Business School Press.

Tufan, Ekrem. (2004). Do Cloudy Days Affect Stock Exchange Returns: Evidence from Istanbul Stock Exchange. Journal of Naval Science and Engineering, Vol. 2, No.1: 117-126.

Wang, K., Y. Li, and J. Erickson, (1997) A New Look at the Monday Effect. The Journal of Finance, 52(5): p. 2171-2186.

Wilkinson, G., (1997) Lunar Cycle and Consultation for Anxiety and Depression in General Practice. International Journal of Social Psychiatry 43(1): 29-34

Yahyazadehfar, M., Abounoori, E., Shababi, H. (2006). Days-of-Week Effect on Tehran Stock Exchange Returns: An Empirical Analysis. Iranian Economic Review, 11(6)

Yalcin, Y. and E.M. Yucel, (2003) The Day of the Week Effect on Stock Market Volatility: Evidence from Emerging Markets.

Yuan, K., Zheng, L., and Zhu, Q. (2006) Are Investor Moonstruck? Lunarphase and Stock Returns. Journal of Empirical Finance (13) 1-23. 


\section{Appendix}

Table 1 Estimates of DOWA for KLCI Daily Series

\begin{tabular}{llllll} 
Model (1) & Monday & Tuesday & Wednesday & Thursday & Friday \\
\hline \hline Coefficient & -0.1212 & 0.1954 & 0.1433 & 0.1828 & 0.2197 \\
& $(0.0042)^{* * *}$ & $(0.0011)^{* * *}$ & $(0.0168)^{* *}$ & $(0.0023)^{* * *}$ & $(0.0020)^{* * *}$ \\
R-Squared & 0.0579 & & & & \\
F-Statistic & 4.2554 & & & & \\
Prob (F-Statistic) & $(0.0020) * * *$ & & & & \\
\hline
\end{tabular}

Note: Figure in the parenthesis is probability values; $(*)(* *)(* * *)$ denotes $(10 \%)(5 \%)(1 \%)$ statistically significance 
Table 2 The Psychological biases on weekend anomaly: dummy interaction model results

\begin{tabular}{|c|c|c|c|c|c|c|c|c|c|c|}
\hline \multirow[b]{2}{*}{ Constant } & \multicolumn{2}{|c|}{ [Day=Monday] } & \multicolumn{2}{|c|}{ [Day=Tuesday] } & \multicolumn{2}{|c|}{ [Day=Wednesday] } & \multicolumn{2}{|c|}{ [Day=Thursday] } & \multicolumn{2}{|c|}{ [Day=Friday] } \\
\hline & -0.8180 & $(0.0732)^{*}$ & -0.7736 & $(0.0917)^{\star}$ & -0.8487 & $(0.0641)^{\star}$ & -0.8056 & $(0.0791)^{*}$ & -0.7990 & $(0.0818)^{*}$ \\
\hline Temp & 0.0379 & $(0.0180)^{\star *}$ & 0.0381 & $(0.0180)^{\star *}$ & 0.0419 & $(0.0092)^{\star * *}$ & 0.0390 & $(0.0153)^{\star *}$ & 0.0396 & $(0.0137)^{\star *}$ \\
\hline Moon & -0.2587 & $(0.0000)^{\star \star *}$ & -0.3525 & $(0.0000)^{\star \star \star}$ & -0.3628 & $(0.0000)^{\star \star \star}$ & -0.3617 & $(0.0000)^{\star \star *}$ & -0.3534 & $(0.0000)^{\star \star *}$ \\
\hline Sent & 0.0265 & $(0.0001)^{\star \star \star}$ & 0.0315 & $(0.0000)^{\star \star *}$ & 0.0213 & $(0.0012)^{\star \star \star}$ & 0.0330 & $(0.0000)^{\star \star \star}$ & 0.0295 & $(0.0001)^{\star * *}$ \\
\hline Herd & -0.0122 & $(0.0911)^{*}$ & -0.0177 & $(0.0167)^{\star \star}$ & -0.0200 & $(0.0071)^{\star \star \star}$ & -0.0150 & $(0.0419)^{\star \star}$ & -0.0214 & $(0.0033)^{\star \star *}$ \\
\hline $\mathrm{Bad}$ & -0.1528 & $(0.0391)^{\star \star}$ & -0.3010 & $(0.0000)^{\star \star *}$ & 0.2640 & $(0.0001)^{\star *}$ & -0.2737 & $(0.0000)^{\star *}$ & --0.2579 & $(0.0001)^{\star \star *}$ \\
\hline World & 0.0796 & $(0.0000)^{\star * *}$ & 0.0812 & $(0.0000)^{\star * *}$ & 0.0807 & $(0.0000)^{\star * *}$ & 0.0817 & $(0.0000)^{* * *}$ & 0.0828 & $(0.0000)^{* * *}$ \\
\hline Temp*Day & 0.0081 & $(0.0920)^{*}$ & -0.0003 & $(0.9542)$ & -0.0058 & $(0.2558)$ & 0.0010 & $(0.8370)$ & -0.0041 & $(0.4277)$ \\
\hline Moon`Day & -0.3862 & $(0.0002)^{\star \star \star}$ & 0.0691 & (0.4999) & 0.1073 & $(0.2974)$ & 0.1196 & $(0.2482)$ & 0.0830 & $(0.4277)$ \\
\hline Sent*Day & 0.0638 & $(0.0018)^{\star \star \star}$ & -0.0228 & $(0.1936)$ & 0.0061 & $(0.7232)$ & -0.0160 & $(0.2402)$ & -0.0041 & $(0.7657)$ \\
\hline Herd ${ }^{\star D}$ ay & -0.0252 & $(0.1379)$ & 0.0027 & $(0.8663)$ & 0.0132 & $(0.4066)$ & -0.0111 & $(0.4930)$ & 0.0238 & $(0.1563)$ \\
\hline BadDay $^{*}$ & 0.2766 & $(0.0788)^{*}$ & -0.1989 & $(0.1197)$ & 0.0397 & $(0.8041)$ & 0.12067 & $(0.4861)$ & 0.0321 & $(0.8416)$ \\
\hline $\mathrm{R} 2$ & 0.0686 & & 0.0613 & & 0.0629 & & 0.0601 & & 0.0610 & \\
\hline Adj R2 & 0.0647 & & 0.0574 & & 0.0590 & & 0.0561 & & 0.0571 & \\
\hline F-statistic & 17.6143 & $(0.0000)^{\star \star *}$ & 15.62081 & $(0.0000)^{\star \star *}$ & 16.04756 & $(0.0000)^{\star \star *}$ & 15.28093 & $(0.0000)^{\star * *}$ & 15.54895 & $(0.0000)^{\star \star \star}$ \\
\hline
\end{tabular}

Note: Figure in the parenthesis is probability values; $(*)(* *)(* * *)$ denotes $(10 \%)(5 \%)(1 \%)$ statistically significance 
Table 3 Psychological biases on weekend anomaly: daily-basis model results

\begin{tabular}{|c|c|c|c|c|c|c|c|c|c|c|}
\hline & \multicolumn{2}{|c|}{ [D=Monday] } & \multicolumn{2}{|c|}{ [D=Tuesday] } & \multicolumn{2}{|c|}{ [D=Wednesday] } & \multicolumn{2}{|c|}{ [D=Thursday] } & \multicolumn{2}{|c|}{ [D=Friday } \\
\hline Constant & -0.0012 & $(0.9216)$ & 0.0002 & $(0.9817)$ & 0.0256 & $(0.3388)$ & 0.0581 & $(0.0246)$ & 0.0249 & $(0.3355)$ \\
\hline Temp & 0.0173 & $(0.0000)^{* * *}$ & 0.0105 & $(0.0000)^{* * *}$ & 0.0007 & $(0.3642)$ & 0.0018 & $(0.0149)$ & 0.0043 & $(0.0000)^{\star \star \star}$ \\
\hline Moon & -0.6440 & $(0.0000)^{\star \star \star}$ & -0.2935 & $(0.0000)^{\star \star *}$ & -0.0439 & $(0.0186)^{\star \star}$ & -0.0487 & $(0.0064)^{\star \star \star}$ & -0.0571 & $(0.0014)^{\star \star *}$ \\
\hline Herd & -0.0355 & $(0.0000)^{* * *}$ & -0.0125 & $(0.0317)^{\star *}$ & -0.0006 & $(0.8445)$ & -0.0045 & $(0.1032)$ & 0.0002 & (0.9298) \\
\hline Sent & 0.0325 & $(0.0001)^{\star \star \star}$ & 0.0114 & $(0.1018)$ & 0.0081 & $(0.1140)$ & 0.0050 & $(0.1651)$ & 0.0090 & $(0.1018)$ \\
\hline Bad & -0.3364 & $(0.0000)^{* * *}$ & -0.0148 & $(0.7977)$ & -0.0315 & $(0.2406)$ & -0.0222 & $(0.3880)$ & -0.0389 & $(0.1287)$ \\
\hline World & 0.1408 & $(0.0000)^{* * *}$ & 0.0087 & $(0.5155)$ & 0.0157 & $(0.0141)^{\star *}$ & 0.0165 & $(0.0071)^{\star * *}$ & 0.0183 & $(0.0026)^{\star \star \star}$ \\
\hline $\mathrm{R} 2$ & 0.12539 & & 0.0323 & & 0.0095 & & 0.0113 & & 0.0266 & \\
\hline Adj R2 & 0.123399 & & 0.0301 & & 0.0072 & & 0.0090 & & 0.0244 & \\
\hline F-statistic & 62.98559 & $(0.0000)^{\star \star \star}$ & 14.65697 & $(0.0028)^{\star \star \star}$ & 4.205076 & $(0.000323)^{* *}$ & 5.0092 & 0.000041 & 12.0166 & $(0.0000)^{* * *}$ \\
\hline
\end{tabular}

Note: Figure in the parenthesis is probability values; $(*)(* *)(* * *)$ denotes $(10 \%)(5 \%)(1 \%)$ statistically significance 
Table 4 Psychological Biases on weekend anomaly: portfolio formation based results

\begin{tabular}{|c|c|c|c|c|c|c|c|c|c|c|}
\hline \multicolumn{11}{|c|}{ Portfolio } \\
\hline & 1 & 2 & 3 & 4 & 5 & 6 & 7 & 8 & 9 & 10 \\
\hline \multirow[t]{2}{*}{ C } & -0.0035 & -0.0014 & -0.0027 & -0.0030 & -0.0044 & -0.0130 & -0.0015 & -0.0006 & -0.0014 & -0.0017 \\
\hline & $(0.9507)$ & $(0.9816)$ & $(0.9421)$ & $(0.9413)$ & $(0.8963)$ & $(0.9547)$ & $(0.9658)$ & $(0.9915)$ & $(0.9762)$ & $(0.9679)$ \\
\hline \multirow[t]{2}{*}{ Temp } & -0.0010 & -0.0044 & 0.0163 & 0.0165 & 0.0182 & -0.0971 & 0.0321 & 0.0078 & -0.0063 & 0.0162 \\
\hline & $(0.9356)$ & $(0.7367)$ & $(0.0484)$ & $(0.0636)$ & $(0.0163)$ & $(0.0551)$ & $(0.0000)$ & $(0.5507)$ & $(0.5544)$ & $(0.0833)$ \\
\hline \multirow[t]{2}{*}{ Moon } & -0.9818 & -1.7016 & -0.9392 & -1.0558 & -0.7759 & 2.3204 & -0.8809 & -0.3099 & -0.9492 & -1.0467 \\
\hline & $(0.0000)$ & $(0.0000)$ & $(0.0000)$ & $(0.0000)$ & $(0.0000)$ & $(0.0146)$ & $(0.0000)$ & $(0.2047)$ & $(0.0000)$ & $(0.0000)$ \\
\hline \multirow[t]{2}{*}{ Herd } & 0.0188 & 0.0658 & -0.0145 & -0.0088 & -0.0499 & 0.4014 & -0.0706 & 0.0017 & 0.0384 & 0.0143 \\
\hline & $(0.6338)$ & $(0.1054)$ & $(0.5733)$ & $(0.7524)$ & $(0.0346)$ & $(0.0112)$ & $(0.0041)$ & $(0.9666)$ & $(0.2449)$ & $(0.6250)$ \\
\hline \multirow[t]{2}{*}{ Sent } & 0.0166 & 0.0607 & 0.0451 & 0.0303 & 0.1114 & -0.2106 & 0.0436 & 0.1427 & 0.0315 & 0.1721 \\
\hline & $(0.6816)$ & $(0.1463)$ & $(0.0890)$ & $(0.2896)$ & $(0.0000)$ & $(0.1954)$ & $(0.0853)$ & $(0.0007)$ & $(0.3537)$ & $(0.0000)$ \\
\hline \multirow[t]{2}{*}{ Bad } & 0.5238 & 0.1032 & 0.1232 & 0.1118 & 0.0358 & -2.3977 & 0.2709 & -0.7373 & 0.0371 & -0.1449 \\
\hline & $(0.0506)$ & $(0.7086)$ & $(0.4817)$ & $(0.5545)$ & $(0.8235)$ & $(0.0257)$ & $(0.1056)$ & $(0.0077)$ & $(0.8688)$ & $(0.4693)$ \\
\hline \multirow[t]{2}{*}{ World } & 0.0977 & 0.0070 & 0.0912 & 0.0128 & 0.1032 & -2.2470 & 0.0637 & -0.0332 & 0.1047 & 0.0700 \\
\hline & $(0.2325)$ & $(0.9339)$ & $(0.0880)$ & $(0.8242)$ & $(0.0355)$ & $(0.0000)$ & $(0.2127)$ & $(0.6937)$ & $(0.1268)$ & $(0.2493)$ \\
\hline $\mathrm{R}^{2}$ & 0.0921 & 0.0225 & 0.0169 & 0.0158 & 0.0256 & 0.0256 & 0.0185 & 0.0083 & 0.0131 & 0.0245 \\
\hline Adj $R^{2}$ & 0.0706 & 0.0202 & 0.0146 & 0.0136 & 0.0234 & 0.0233 & 0.0163 & 0.0060 & 0.0109 & 0.0222 \\
\hline F-statistic & 4.0880 & 10.0695 & 7.5347 & 7.0511 & 11.5396 & 11.5197 & 8.2745 & 3.6663 & 5.8359 & 10.8359 \\
\hline Probability & $(0.0004)$ & $(0.0000)$ & $(0.0000)$ & $(0.0000)$ & $(0.0000)$ & $(0.0000)$ & $(0.0000)$ & $(0.0013)$ & $(0.0000)$ & $(0.0000)$ \\
\hline
\end{tabular}

Note: Figure in the parenthesis is probability values which showing the significance level; Figure without parenthesis is the coefficient value.

Table 5 Recapitulation of Day Interaction with Psychological Biases ${ }^{4}$

\begin{tabular}{lcccccccccc}
\hline & 1 & 2 & 3 & 4 & 5 & 6 & 7 & 8 & 9 & 10 \\
\hline Tuesday & - & - & W & - & W & S, W & - & - & - & - \\
Wednesday & - & S & S, W & S & S, W & S, W & S & - & - & - \\
Thursday & - & - & W & - & W & S, W & - & - & - & - \\
Friday & - & - & W & - & W & S, W & - & - & - & - \\
\hline
\end{tabular}

Note: 1-10 are the size-based portfolio formation from small to big; M is Moon; S is Sentiment; B is Bad News; H is Herd; $\mathrm{W}$ is the World Effect. We put the psychological variables here if it is significant at $1 \%$ level.

\footnotetext{
${ }^{4}$ The details of the outputs are upon request. You can email to raye_brahm@yahoo.com. We recap the tables due to page limitation.
} 